\title{
INTRODUCCIÓN
}

\section{El imperativo del Desarrollo}

\section{Fernando Delage'}

En marzo de 1946, a iniciativa de la Compañía de Jesús, nació Fomento Social: Revista de Sociología y de Moral Económica. Desconocemos si el subtítulo era un guiño a Adam Smith, filósofo moral antes que economista según se definió a sí mismo, pero el sabio escocés habría compartido con seguridad el objetivo que anunciaba la publicación en su primer número: "moralizar las relaciones económico-sociales de la Humanidad". En cierto modo ese era también el propósito de quienes por aquel entonces habían diseñado un nuevo orden internacional tras concluir la Segunda Guerra Mundial.

Los fundadores de las Naciones Unidas, la organización en el centro de dicho orden, pretendieron corregir las deficiencias de su antecesora, la Sociedad de Naciones, pero manteniendo sus mismos fines. Así, su Carta constitutiva reafirmaba el compromiso con "la igualdad de derechos de hombres y mujeres y de las naciones grandes y pequeñas". La ONU y el conjunto de instituciones establecidas entre 1944 (las de Bretton Woods) y 1945 respondían al equilibrio de poder del sistema internacional de postguerra, pero no eran un fin en sí mismas: aspiraban a intentar asegurar un acuerdo entre las grandes potencias sobre un principio compartido de justicia (Gaddis, 2005: 158-159). Se trataba, no obstante, de una pretensión difícilmente realizable, pues si para Estados Unidos "justicia" significaba democracia, respeto a los derechos individuales y libre mercado, para la Unión Soviética de Stalin implicaba, por el contrario, la aceptación de un régimen autoritario, la dictadura del proletariado y una economía planificada.

"Nuestra política no está dirigida contra ningún país o doctrina, sino contra el hambre, la pobreza, la desesperación y el caos", declaró el general Marshall al

' Fernando Delage es director del Departamento de Estudios Internacionales, Universidad Loyola Andalucía. 
anunciar el Plan que lleva su nombre en junio de 1947. Pero el objetivo primordial era la reconstrucción de una Europa devastada por la guerra, con el fin de prevenir consecuencias políticas como las causadas por la Gran Depresión a partir de 1929. Pese a la urgencia de la recuperación económica del Viejo Continente, fue también en el contexto de rivalidad ideológica de la Guerra Fría cuando arrancó el proceso de descolonización y, con él, irrumpieron los primeros debates sobre las causas de la desigualdad y el subdesarrollo, asuntos de los que -junto a la evolución del pensamiento social cristiano en España- se ha ocupado Revista de Fomento Social a lo largo de su historia.

\section{De los primeros debates a la Agenda 2030}

Las dos superpotencias defendieron el fin de los imperios, pero quisieron influir en la orientación política de los nuevos Estados independientes (englobados bajo la categoría de "Tercer Mundo"). Entre sus prioridades fundamentales, todos ellos compartían la necesidad de sentar las bases para su crecimiento económico más allá de los antiguos vínculos coloniales. Pese a la diversidad de puntos de vista sobre la cuestión, dos grandes teorías vinieron a sintetizar los términos de la discusión hasta la década de los setenta. La primera de ellas, la teoría de la modernización, representada por Walt Rostow (profesor del MIT y asesor del presidente Kennedy), consideraba que la tarea del desarrollo consistía en facilitar la transición hacia el crecimiento económico de las sociedades más pobres mediante las inversiones, la tecnología y los valores de Occidente (Rostow, 1960). La teoría de la dependencia, uno de cuyos principales exponentes fue el argentino Raúl Prebisch (secretario ejecutivo de la CEPAL entre 1950 y 1963), partía de la premisa opuesta: las naciones menos favorecidas lo eran en parte por encontrarse estructuralmente subordinadas a los países occidentales (Prebisch, 1959). Su desarrollo dependía por tanto de encontrar la manera de protegerse de esos condicionantes y buscar otras alternativas.

La excesiva generalización de ambos enfoques y el ascenso de las nuevas economías industrializadas de Asia oriental -fenómeno que no podía explicar ninguna de las dos teorías- recondujeron el debate hacia un examen más individualizado de cada caso. La propia evolución de la economía internacional iba a conducir, por otra parte, a sucesivos giros en relación con las estrategias de desarrollo. Si la crisis de la deuda de 1982 propició la adopción de ajustes estructurales bajo la convicción de que las políticas de reformas y un menor intervencionismo estatal acelerarían el crecimiento, el impulso de la globalización en la década de 
los noventa dio paso a una etapa de renovado optimismo, que concluiría con el estallido de la crisis financiera global en 2008.

Hasta entonces, la lectura más positiva había hecho hincapié en la reducción global de los índices de pobreza desde los años ochenta y en el ascenso de las economías emergentes (Radelet, 2015). El porcentaje de pobreza absoluta se redujo del 43 por cien de la población mundial en 1990 al 22,4 por cien en 2008 (y al 11 por cien en 2015), según los datos del PNUD, mientras que el centro de gravedad de la economía internacional comenzó a desplazarse desde los países de la OCDE hacia Asia y países del Sur, cuyo porcentaje del PIB global se incrementó del 27 por cien en 1950 al 47,9 por cien en 2010. El desglose era notablemente desigual, sin embargo: África pasó del 3,8 por cien al 3,4 por cien del PIB mundial en 2008; América Latina del 7,8 por cien al 7,9 por cien en el mismo periodo; mientras que la cifra representada por Asia aumentó del 15,4 por cien al 38 por cien (Nayyar 2013: 50). Al margen de las diferencias metodológicas sobre la medición de los índices de pobreza o del ritmo de crecimiento -que podían dar resultados distintos de los mencionados-, más significativa resultaba la aparición de un nuevo fenómeno: aunque un número no pequeño de naciones han alcanzado durante los últimos 40 años un nivel de ingresos medios, los beneficios de su crecimiento no se han extendido a los más pobres en dichas sociedades (Kanbur y Sumner, 2012).

Los efectos de este incremento generalizado de la desigualdad se exacerbarían con la recesión de 2008, primero, y con la pandemia del coronavirus, después. La crisis financiera global provocó una significativa reducción de los flujos de capital hacia las economías en desarrollo, circunstancia que-agravada por la caída en los precios de las materias primas pocos años más tarde-empeoraría las balanzas de pagos y el déficit de buena parte de estas naciones. La pandemia, por su parte, no sólo ha confirmado la desigualdad estructural en y entre los países, sino que puede marcar un dramático retroceso con respecto a los avances de las últimas décadas, afectando de manera especial a los Estados más frágiles y a las sociedades más vulnerables (Eisentraut et al., 2020; Shah, 2021).

El mundo de hoy no puede ser más diferente del de 1946. El número de Estados casi se ha cuadruplicado; el continente entonces más pobre -Asia- es hoy el centro del dinamismo económico mundial; y la interdependencia global, la digitalización y la Cuarta Revolución Industrial han creado un escenario que hace 75 años eran pura ciencia ficción. La mejora en numerosos índices es innegable: la alfabetización aumentó del 36 por cien de media mundial en 1950 al 83 por cien en 2010; la mortalidad infantil se ha reducido en la práctica mayoría de los países; y la esperanza de vida se ha elevado de los 46 años de 1950 a los 72 en 
2017. Pero dos tercios de las naciones dependen de la ayuda internacional para proporcionar servicios básicos a su población (Chowdhury, 2018), y tampoco los países más desarrollados se libran de la lacra de la desigualdad. Los objetivos de Revista de Fomento Social siguen pues plenamente vigentes.

Con todo, una diferencia sustancial con respecto a hace siete décadas ha sido la gradual transformación del propio concepto de desarrollo. Partiendo de un enfoque aún economicista, los años sesenta fueron declarados como el Decenio de las Naciones Unidas para el Desarrollo, seguido por un II Decenio en la década de los setenta, periodo en el que se convocaron las primeras Conferencias de las Naciones Unidas sobre Comercio y Desarrollo (UNCTAD) en 1964 y 1968, y la Asamblea General propuso un Nuevo Orden Económico Internacional en 1974. Estas iniciativas, impulsadas por los países menos desarrollados, se encontraron con la resistencia de las naciones industrializadas pero permitieron ciertas mejoras, como por ejemplo el establecimiento de sistemas de preferencias comerciales más abiertos, asunto del que también se ocuparía la cumbre Norte-Sur (también el lenguaje cambió: del Tercer Mundo se pasó al "Sur Global") celebrada en Cancún en 1981. Hubo que esperar, no obstante, al fin de la Guerra Fría para que se abriera paso una reconsideración de las cuestiones de desarrollo, para incluir en el mismo la salud, la educación o, incluso, las libertades políticas. El primer informe de Desarrollo Humano del PNUD simbolizó el comienzo de esta etapa, a partir de la cual el foco pasó de las economías nacionales al bienestar de las personas, aproximación a la que también había conducido la reflexión de los expertos, entre los que destacó de manera muy especial el economista indio y premio Nobel Amartya Sen (PNUD, 1990; Sen, 1999).

Estas nuevas perspectivas sobre el desarrollo fueron las que llevaron a la adopción, en el año 2000, de la Declaración y los Objetivos de Desarrollo del Milenio, actualizados por la ONU en 2015 en la Agenda 2030 para el Desarrollo Sostenible, documento en el que se indica:

El desarrollo sostenible parte de la base de que la erradicación de la pobreza en todas sus formas y dimensiones, la lucha contra la desigualdad dentro de los países y entre ellos, la preservación del planeta, la creación de un crecimiento económico sostenido, inclusivo y sostenible y el fomento de la inclusión social están vinculados entre sí y son interdependientes (Asamblea General de las Naciones Unidas, 2015).

Este es el resultado hasta la fecha de un largo recorrido que permite a Revista de Fomento Social, en su número 300, examinar el estado de la cuestión desde la ciencia económica; analizar la evolución durante estas décadas de los continentes menos favorecidos; describir los cambios producidos en la política de ayuda al 
desarrollo de los principales donantes; y concluir con la insoslayable dimensión ética del desarrollo, principal seña de identidad de la revista desde sus orígenes.

\section{Un examen comparativo}

En el primero de los estudios, Pedro Caldentey y José Juan Romero hacen hincapié en la positiva evolución que se ha producido con respecto a la teoría y la práctica del desarrollo. No sólo se ha pasado desde una perspectiva economicista a un enfoque multidimensional, como ya se indicó con anterioridad, sino que cabe apreciar una mayor aproximación al interés común, a la vez que se ha consolidado un consenso global, articulado en la Agenda 2030. El acuerdo sobre sus objetivos ha sido posible -señalan los autores- porque se ha producido, por una parte, un cierto grado de convergencia entre las diferentes teorías económicas que ha hecho posible que se preste atención de manera simultánea a los equilibrios macroeconómicos y a los más desfavorecidos; $y$, por otra, porque se ha propiciado la flexibilidad necesaria para ajustar la relación entre Estado y mercado, y poder atender así las necesidades del desarrollo.

La agenda se ha ampliado por lo demás, con asuntos hoy prioritarios como la desigualdad, el cambio climático, la transición tecnológica y energética, o la política industrial. La pandemia del coronavirus ha demostrado, no obstante, la debilidad de muchos de los avances logrados, comprometiendo de nuevo el futuro de los más vulnerables. La ambiciosa formulación de los Objetivos del Desarrollo Sostenible, concluyen Caldentey y Romero, puede hacernos dudar de su cumplimiento en este contexto de crisis. Pero el salto dado desde el dogmatismo anterior a la década de los noventa-que claramente perjudicaba la eficacia de las políticas-, al consenso global logrado en nuestros días, permite no renunciar del todo al optimismo. Sigamos, eso sí, la recomendación de los autores para corregir el predominio de las teorías y publicaciones sobre desarrollo realizadas por los países más industrializados y abrir el espacio que les corresponde a las voces del mundo más desfavorecido.

Al examinar de manera comparativa la evolución del desarrollo durante las últimas décadas, Asia es la región que ha experimentado una mayor transformación, como analiza en su artículo Robert Wihtol. En 1960, en el Asia en desarrollo (es decir, excluyendo a Japón, Australia y Nueva Zelanda), con un PIB per cápita de 330 dólares, la pobreza afectaba al 68 por cien de la población. Todavía en 1970, la educación primaria sólo incluía al 72,3 por cien, y la universitaria al 2,4 por cien, 
de la población. En 2018, el PIB per cápita había alcanzado los 5.000 dólares y la pobreza se había reducido al 6,9 por cien. Los índices de educación primaria superaban el 93 por cien, y la universitaria el 34,3 por cien. Un alto y sostenido ritmo de crecimiento en un continente que incluye a China e India-dos países que suman el $\mathbf{4 0}$ por cien de la población mundial- ha hecho del ascenso de Asia la gran historia económica y geopolítica de nuestro tiempo.

Las razones de este éxito siguen siendo objeto de discusión entre los expertos, pero, como subraya Wihtol, diversos factores pueden amenazar su continuidad. Destacan entre ellos el desafío demográfico que representa el rápido envejecimiento en buena parte de sus naciones; el reto de mantener la competitividad y superar la "trampa de los ingresos medios" en un contexto global marcado por un giro en la dinámica de la globalización; las amenazas a la estabilidad regional derivadas de disputas territoriales no resueltas y de la confrontación entre Estados Unidos y China; o la debilidad de las instituciones políticas, un aspecto este último de especial relevancia. Mientras la literatura sobre el "milagro" asiático ha hecho hincapié en las variables económicas, la infraestructura social y la modernización política se encuentran lejos de haberse completado. De ellas depende en gran medida, sin embargo, la sostenibilidad del desarrollo en el continente en el futuro.

América Latina y el Caribe es, escribe Jorge Mario Martínez, la región más desigual del mundo, sin que haya se logrado reducir la brecha que le separa de los países más ricos, una circunstancia que no ha cambiado pese a los sucesivos giros en las políticas seguidas. En 1990 el PIB per capita de la región era el 15 por cien del de Estados Unidos; en 2018, había caído al 14 por cien. En 2018, alrededor del 30,1 por cien de la población estaba bajo la línea de pobreza, mientras que un 10,7 por cien se encontraba bajo el umbral de la pobreza extrema. Mientras, el crecimiento de la productividad se ha reducido con el tiempo: si, por ejemplo, en Argentina, Brasil y México aumentó como media un 1,1 por cien, un 3,7 por cien y un 1,8 por cien, respectivamente, entre 1965 y 1981 , las cifras fueron del 0,4 por cien, 1,3 por cien, y 0,06 por cien entre 1982 y 2010. Como referencia comparativa, el incremento de la productividad de Corea del Sur durante esos dos periodos fue del 4,7 por cien y del 4,3 por cien, respectivamente.

La crisis de 2008 marcó el fin de un ciclo expansivo y, desde entonces, la región no ha logrado un crecimiento sostenido, ni de su producción industrial ni de su comercio. Tampoco la inversión extranjera directa ha retomado los volúmenes registrados en la primera década del siglo. Más graves son, con todo, los problemas sociales y medioambientales de carácter estructural puestos en evidencia por la pandemia, por no hablar del alto coste que están teniendo los efectos del 
calentamiento global. El subcontinente requiere una reconsideracion integral de las fuerzas económicas, orientada al impulso de nuevas industrias, al establecimiento de nuevos marcos regulatorios - del comercio al medio ambiente y la energía-, además de apoyar a sectores esenciales, garantizar unos ingresos mínimos y avanzar en la igualdad de derechos. Si se impone una prioridad en la estrategia de desarrollo latinoamericana, ésta debe ser la atención a la desigualdad.

Sesenta años después de la independencia de buena parte de los actuales Estados africanos, María Ángeles Alaminos analiza la evolución del continente prestando especial atención a la relación entre desarrollo político y económico. Partiendo del legado colonial, la autora identifica los principales factores que han marcado la formación de dichos Estados, y su control por parte de una elite política que ha monopolizado igualmente el acceso a los recursos. Uno de los efectos de este sistema neopatrimonialista ha sido la prioridad otorgada a las zonas urbanas respecto a las regiones periféricas, sumiendo en la pobreza a los territorios más alejados de la administración central.

Pese a la abundancia de recursos, África es el continente con el mayor número de países menos desarrollados y los peores indicadores macroeconómicos. La falta de diversificación de sus economías y la dependencia de la exportación de productos primarios ha sido un obstáculo para una transformación estructural que requeriría tanto una mayor industrialización como la superación del enorme déficit en infraestructuras. Sucesivas iniciativas para la erradicación de la pobreza, la promoción del crecimiento y la inserción de África en la economía internacional han tenido resultados limitados, lo que ha conducido en tiempos recientes a la promoción de nuevos enfoques orientados al desarrollo sostenible y la integración regional, como los perseguidos por la Agenda 2063 de la Unión Africana. La irrupción de China como actor externo comprometido con la industrialización del continente (frente a lo que Pekín denomina el "paternalismo" de Occidente), y -desde la perspectiva interna- la creciente movilización social contra la corrupción y las estructuras de desigualdad, son dos de las principales variables que determinarán la próxima etapa de la agenda de desarrollo africana.

El mundo árabe es, señala Jesús Núñez, una bomba a punto de explotar. Los datos no dejan mucho espacio a la esperanza. Siguiendo como referencia el Índice de Desarrollo Humano del PNUD, aunque todos los países árabes obtuvieron ciertas mejoras entre 1980 y 2010 -con ganancias notables en educación y salud, y menos significativas en cuanto a los ingresos-, el efecto combinado de la crisis económica de 2008 y la inestabilidad política generada por las "primaveras árabes" ya supuso en el periodo 2010-2014 una caída global en dicho índice de más del 50 por 
cien en relación con la década anterior. Una derivada inmediata de esa caída ha sido el aumento de las que ya eran notorias brechas de desigualdad: un informe de 2018 del Banco Mundial indicaba que Oriente Próximo y Norte de África era la única región del planeta en la que la pobreza extrema había aumentado en el periodo 2011-2015, pasando del 2,7 por cien al 5 por cien. A la espera del efecto adicional que está provocando la pandemia, el Banco Mundial confirmó de nuevo esa negativa evolución de la pobreza extrema en 2020, hasta alcanzar el 7,2 por cien de la población.

De manera simultánea se han deteriorado los sistemas de salud y educación, y se ha hecho cada más difícil el acceso al mercado laboral. La incapacidad de traducir los avances en el plano educativo en empleos dignos para una población mayoritariamente joven, en naciones que mantienen al mismo tiempo un alto ritmo de crecimiento demográfico, es una de las principales causas de la tensión social y políitica. En 2014, el desempleo juvenil en los países árabes (29,73 por cien) era más del doble de la media mundial (13,99 por cien). Sin acciones drásticas, las economías árabes no podrán generar los 60 millones de empleos necesarios para absorber a la población en edad laboral. En el mundo árabe se acusa de manera especial el dilema de que no puede haber desarrollo sin seguridad, ni seguridad sin desarrollo, y ni uno ni otro sin un pleno respeto de los derechos humanos.

Para algunas regiones, el desarrollo implica, desde la perspectiva económica, un cambio estructural que debe conducir a la superación de la condición de periferia y de las características estructurales que limitan el crecimiento a largo plazo. Más díficil resulta, sin embargo, poner fin a conflictos enraizados y modernizar estructuras y prácticas políticas. Si bien una parte fundamental de esa tarea es interna, las políticas de ayuda al desarrollo no siempre se han definido conforme a ese doble objetivo. Después de todo, los donantes también tienen sus intereses y preferencias geográficas y políticas, como examina el siguiente bloque de contribuciones.

\section{Teoría y práctica de la ayuda al desarrollo}

A partir de la segunda mitad del siglo XX, escriben José Antonio Sanahuja y Augusto Delkáder-Palacios, el actor decisivo en la configuración de la agenda global del desarrollo, tanto en el plano bilateral como a través de las instituciones internacionales, fue Estados Unidos. Sus políticas e instrumentos marcaron asimismo el comportamiento de otros donantes, si bien la evolución de su ayuda exterior ha estado vinculada a lo largo del tiempo a fines muy diversos. Si la seguridad 
nacional y la contención del comunismo fueron prioritarios en una primera etapa, posteriormente se ampliaron los objetivos a la lucha contra el narcotráfico y el terrorismo, a la promoción de la democratización o a la apertura de los mercados de los países en desarrollo al comercio y la inversión extranjera.

Como es lógico, el sistema de cooperación y ayuda al desarrollo ha sido un reflejo de la estructura de la sociedad internacional y de sus dinámicas históricas. El primer sistema, como se indicó, nació bajo el doble condicionante de la bipolaridad y del proceso de descolonización. Con el fin de la Guerra Fría y el impulso de la globalización, se multiplicó el número de actores en juego y Occidente fue perdiendo capacidad para seguir definiendo por sí solo las reglas. Estados Unidos en particular, subrayan los autores, ya no puede desempeñar el papel dominante de otras épocas. La crisis de la globalización neoliberal, la redistribución de poder en el sistema internacional y el auge de las interacciones de naturaleza transnacional crean, no obstante, una oportunidad para dar forma a nuevas dinámicas en la ayuda exterior, desde una lógica cosmopolita y enfocada al multilateralismo, los derechos y la sostenibilidad como principios rectores.

Iliana Olivié y María Santillán analizan la política de ayuda al desarrollo de la Unión Europea, uno de los pilares centrales de su papel internacional. Al ser el primer donante mundial por volumen de ayuda desembolsada, es éste, en efecto, uno de los ámbitos -junto al económico y comercial- en el que puede ejercer un liderazgo significativo frente a los otros dos grandes actores globales, Estados Unidos y China. Quizá sea ésta una de las razones, señalan las autoras, de que, a medida que se consolida la rivalidad estratégica global entre Washington y Pekín, la ayuda de la UE haya sumado objetivos geopolíticos a los tradicionales de la solidaridad, la erradicación de la pobreza y el desarrollo humano.

Estos últimos han estado en el centro de la política europea a lo largo del tiempo, y siguen formando parte de las prioridades recogidas por el Nuevo Consenso Europeo de Desarrollo de 2017. La ayuda de la Unión, declara el documento, se orienta a las personas (pobreza, desigualdad, desarrollo humano, igualdad de género, migración, cultura, educación o salud); el planeta (medioambiente, transición ecológica, recursos naturales o energía sostenible); la prosperidad (comercio, crecimiento sostenible o transformación digital); la paz (democracia, Estado de Derecho, Derechos Humanos; y la asociación (con el fin de crear las alianzas necesarias con la sociedad civil o la comunidad de donantes bilaterales y multilaterales en aras del desarrollo global). Los objetivos de la UE como donante son, por tanto, los suscritos por el conjunto de la comunidad internacional en el marco de las Naciones Unidas. Un examen pormenorizado revela, no obstante, 
otros elementos: la distribución geográfica de la ayuda, dirigida en su mayor parte al Norte de África y Oriente Próximo, hace hincapié en la promoción de la democracia y la buena gobernanza en los países destinatarios, así como en la prevención de la migración.

Nikolay Murashkin se ocupa de Japón, un país que, de derrotado en la Segunda Guerra Mundial, experimentó una rápida recuperación y modernización, en el contexto de un alto ritmo de crecimiento y de una política exterior pacifista, uno de cuyos elementos primordiales iba a ser la cooperación al desarrollo. Tras examinar la literatura sobre el tema, Murashkin analiza la evolución de la ayuda japonesa, identificando las principales características de cada etapa.

En la década de los cincuenta, la cooperación japonesa aparecía vinculada a un mismo tiempo a las reparaciones de guerra a los Estados vecinos que ocupó, y a la propia recuperación económica nacional. El aumento de su prosperidad permitió ampliar el sistema de ayuda al desarrollo a lo largo de los años. Japón creó el Fondo de Cooperación Económica con el Exterior en 1961 (antecedente de la Japan International Cooperation Agency (JICA), establecida en 1974); se incorporó al Comité de Ayuda al Desarrollo el mismo año ly a la propia OCDE en 1964); y lideró desde su fundación en 1966 el Banco Asiático de Desarrollo. La gradual expansión de su ayuda al exterior tras su consolidación como una de las grandes economías del planeta hizo de Japón el mayor donante mundial en 1989 (estatus que mantendría hasta el año 2000). Tras el fin de la Guerra Fría, su política de cooperación adquirió una nueva dimensión, al subrayar un doble objetivo -la seguridad humana y un crecimiento de calidad-y extender el alcance geográfico de su ayuda. Así, por ejemplo, en 1993 se lanzó la Conferencia Internacional de Tokio sobre Desarrollo en África, una iniciativa aún influyente en el escenario global del desarrollo.

Aunque durante los años ochenta y noventa, una de las principales críticas de europeos y norteamericanos a la política japonesa fue su hincapié en las infraestructuras, es éste un aspecto que ha adquirido una notable relevancia en la actual agenda internacional, en parte como respuesta de las democracias industrializadas a la iniciativa de la nueva Ruta de la Seda promovida por China. El déficit en infraestructuras es uno de los principales obstáculos al crecimiento de no pocos países, mientras que -al insistirse en la sostenibilidad financiera y medioambiental, así como en las condiciones laborales, de los proyectos- se ofrece una alternativa a la estrategia geoeconómica de Pekín, que redunda asimismo en los objetivos geopolíticos de asegurar un orden internacional y regional basado en reglas y valores democráticos. 
China, objeto del artículo de Georgina Higueras, representa el caso excepcional de una nación que, de ser un tradicional receptor de ayuda, ha pasado a convertirse en un importante donante, en coherencia con su ascenso al centro de la economía mundial. Las cifras hablan por sí solas: entre 1980 -cuando la renta per cápita china era inferior a la media de los países africanos-y el año 2000, China recibió 38.000 millones de dólares del exterior; entre 2013 y 2018, su ayuda al desarrollo de los países menos favorecidos alcanzó una cifra aproximada a los 7.000 millones de dólares anuales. Entre 2000 y 2014 concedió, además, unos 350.000 millones de dólares en préstamos sin intereses, prestamos en condiciones favorables y subvenciones.

Pekín ha publicado hasta la fecha tres libros blancos sobre su ayuda exterior (en 2011 , 2014, y en enero de este mismo año) y, en 2018, creó la Agencia China de Cooperación Internacional para el Desarrollo, con el fin de simplificar una estructura administrativa en la que anteriormente habían compartido competencias más de 23 ministerios y comisiones. Además de vincular sus acciones en materia de desarrollo a iniciativas como la nueva Ruta de la Seda, la República Popular ha subrayado su papel al frente de la cooperación Sur-Sur y su defensa de "un nuevo modelo de relaciones internacionales basadas en el respeto mutuo, la igualdad y la justicia". Tras haber alcanzado el hito histórico de sacar de la pobreza a 800 millones de personas en menos de medio siglo y haber erradicado la pobreza extrema, Pekín se ve legitimado para promover un concepto de desarrollo que ha definido como "innovador, coordinado, ecológico, abierto e inclusivo" en su último Plan Quinquenal, aprobado en octubre de 2020. Sobre la base de su propia experiencia, el presidente Xi Jinping quiere priorizar la lucha contra la pobreza desde la Agenda 2030. "No habrá desarrollo sostenible en el mundo mientras unos países sean cada vez más ricos y otros se hundan cada vez más en la pobreza y el atraso", suele repetir Xi en sus discursos. Construir "una comunidad de futuro compartido para la humanidad" es uno de sus lemas favoritos, si bien no deja de resultar contradictorio con los altos índices de desigualdad que se registran en China.

Dos artículos examinan a continuación la política de cooperación española. Mónica Colomer describe su origen en la puesta en marcha de los procesos de paz de Centroamérica, tras los acuerdos de Esquipulas en los años noventa. España ofreció su apoyo a partir de la experiencia de su propia transformación política, social y económica desde la transición. Ese acompañamiento a los procesos de consolidación democrática, a la construcción y modernización del Estado y sus instituciones, y a políticas de lucha contra la pobreza, se hizo extensible a otros países de la región. Fue la $A E C I D$, adscrita al ministerio de Asuntos Exteriores 
desde su creación en 1988, quien asumió la gestión y la ejecución de la política de cooperación internacional para el desarrollo.

Los sucesivos Planes Directores, elaborados cada cuatro años, han establecido el marco estratégico y las orientaciones para la acción de la cooperación española. Una de sus señas de identidad ha sido el esfuerzo orientado a la gobernabilidad democrática y el fortalecimiento institucional con el fin de garantizar un marco adecuado de políticas públicas. La cooperación española ha mantenido, por otra parte, un enfoque regional, complementario de su acción bilateral, basado en la convicción de que la integración ayuda a generar cambios y a vencer resistencias internas. Son procesos que favorecen el desarrollo económico y social, al armonizar normas y políticas que permiten adoptar respuestas coordinadas frente a problemas comunes. España ha impulsado por ello una línea de trabajo dirigida al fortalecimiento de los procesos de integración regional: en América Latina y el Caribe con la Comunidad de Estados del Caribe, el Sistema de la Integración Centroamericana (SICA), MERCOSUR, la Comunidad Andina y la Alianza del Pacífico; $y$, en África, con la Comunidad Económica de Estados de África Occidental y con la Unión Africana. Por lo demás, España no ha sido una excepción y ha adoptado un plan de acción para hacer seguimiento del cumplimiento de los objetivos de la Agenda 2030.

En un mundo caracterizado por la creciente importancia de los actores no estatales, no podía faltar la voz de las ONG dedicadas al desarrollo (ONGD), asunto sobre el que escribe Jose María Vera. Estas organizaciones nacieron en España en los años cincuenta y sesenta, vinculadas a movimientos católicos-como Cáritas y Manos Unidas- y a las órdenes religiosas. En una primera etapa lo social se combinó con lo pastoral, en organizaciones orientadas sobre todo a dar apoyo a los misioneros españoles en el entonces llamado Tercer Mundo. Con posterioridad al Concilio Vaticano II, en la era del estructuralismo económico y del despliegue de luchas sociales, algunos grupos católicos apostaron por una mirada más profunda a las causas del subdesarrollo y la pobreza, mientras que hubo que esperar a la transición democrática para la creación de organizaciones no religiosas. La Coordinadora Española de ONGD se fundó en 1986, y a partir de entonces se dio forma a las primeras acciones conjuntas como sector.

Un nuevo hito se produjo con la aprobación, en 1998, de la Ley de Cooperación Internacional para el Desarrollo, un texto aún en vigor. Sin abandonar la prioridad de los países del Sur, las ONGD se abrieron a cuestiones como la cancelación de deuda, la propiedad intelectual, los derechos laborales o el trabajo infantil. Tras unos años de crecimiento, la crisis de 2008 tuvo, no obstante, un efecto demoledor 
para la cooperación española y, por tanto, para las ONGD. En este estado de debilidad y de cierta desorientación, la década siguiente vendría definida por la Agenda 2030 y su concepción universal. En un contexto agravado de manera exponencial por las consecuencias socioeconómicas de la pandemia, las ONG seguirán siendo relevantes en temas tan dispares como la financiación del desarrollo, la inversión sostenible, el cambio climático en todas sus facetas, el mercado laboral, la fiscalidad, la equidad racial y de género, o los conflictos.

\section{Una mirada ética}

Cierra el número la reflexión de Ildefonso Camacho sobre la perspectiva ética del desarrollo, un aspecto que, como bien señala, no resultaba tan evidente a mediados del siglo XX como lo es hoy. Fue el resultado de quienes empezaron a preguntarse no cómo lograr el desarrollo, sino "¿qué desarrollo?". Camacho examina este proceso tomando como referencia sucesivos hitos en la evolución del pensamiento social cristiano, vinculados a su vez al contexto histórico y a las principales tendencias en el pensamiento sobre el desarrollo en cada momento. El pensamiento de la Iglesia ha contribuido con sus aportaciones a la elaboración de una ética del desarrollo hecha desde perspectivas no religiosas, y que en la actualidad forma parte del consenso de la comunidad internacional.

Desde la Pacem in terris de Juan XXIII y las primeras manifestaciones sobre el "desarrollo de los pueblos" bajo una óptica cristiana a la "casa común" del Papa Francisco, de las ideas del dominico Louis-Joseph Lebret a las teorías de su discípulo Denis Goulet, fue tomando cuerpo una ética del desarrollo que se sintetiza en la siguiente fórmula: desarrollo humano integral, solidario y sostenible. Es la persona quien está en el fin de todo desarrollo, por lo que se trata de "capacitar a cada sujeto para que haga realidad sus aspiraciones en todos los niveles de la existencia humana (desarrollo integral)"; un enfoque que tampoco puede separarse del desarrollo de todos (solidario) ni prescindir de cuidar el entorno natural (sostenible). Es una formulación que refleja la evolución del pensamiento sobre estos temas a lo largo de 75 años, y que muestra cómo el desarrollo ha dejado de ser un tema que afecta a un colectivo delimitado de personas y pueblos para ser una tema transversal: "afecta a todo ser humano e invita a cuestionar estilos de vida demasiado incuestionados".

Es responsabilidad de los líderes políticos mundiales, ante todo, crear las condiciones que puedan hacer posible un desarrollo auténtico y pleno. Una de las 
cuestiones centrales del orden global en la segunda mitad del siglo XX tuvo que ver con la lucha de las naciones no occidentales contra las estructuras y relaciones de desigualdad. El fin de la Guerra Fría, la redistribución de poder en curso, la heterogeneidad del mundo en desarrollo y la influencia adquirida por algunas de las grandes economías emergentes han transformado la agenda global. No obstante, como en 1945, la comunidad internacional afronta el mismo desafío de construir un orden orientado al servicio de la paz, la prosperidad y la justicia. Si al terminar la Segunda Guerra Mundial los conceptos de justicia mantenidos por Truman y Stalin resultaban antitéticos, otro tanto puede decirse de los mantenidos por Estados Unidos y China -cada uno de ellos acompañados por unas $\mathrm{U}$ otras naciones- al arrancar la tercera década del siglo XXI. Una novedad es que China ha demostrado que el desarrollo (económico) es posible sin democracia; un modelo que resulta atractivo para no pocos gobernantes, aunque plantea considerables dudas sobre su viabilidad a largo plazo.

Con todo, una transformación aún mayor deriva del hecho de que la multiplicación de los problemas transnacionales ha acabado con la concepción clásica del interés "nacional", en la actualidad inseparable de los globales, como bien reflejan la pandemia o el cambio climático. También la pobreza y la desigualdad. Todos los Estados se necesitan para su desarrollo social, económico y político, al afectar éste de manera directa a la estabilidad del sistema internacional y a la sostenibilidad del planeta. Comprometerse con los demás no es en consecuencia generosidad ni solidaridad, sino un imperativo ligado a un mundo interdependiente, en el que toda aproximación a la justicia debería comenzar por intentar situarse "desde la mirada de los otros", como aconsejó Adam Smith en su Teoría de los Sentimientos Morales.

\section{Bibliografía}

Asamblea General de las Naciones Unidas (2015, 25 septiembre). "Transformar nuestro mundo: la Agenda 2030 para el Desarrollo Sostenible" (A/R/70/1), https:// documents-dds-ny.un.org/doc/UNDOC/GEN/N15/291/93/PDF/N1529193. pdf? OpenElement

Chowdhury, A. (2018). The Myth of International Order: Why Weak States Persist and Alternatives to the State Fade Away, Oxford, Oxford University Press.

Elsentraut, Sophie, et al. (2020). Polypandemic: Special Edition of the Munich Security Report, Munich Security Conference, noviembre 2020, https://doi. org/10.47342/CJAO3231 
GADDIS, J. L. (2005). The Cold War, Londres, Allen Lane.

Kanbur, R. y Sumner, A. (2012). "Poor Countries or Poor People?" Journal of International Development, 24 (6): 686-695.

NaYYAR, D. (2013). Catch Up: Developing Countries in the World Economy, Oxford, Oxford University Press.

PNUD (1990). Desarrollo Humano Informe 1990, http://hdr.undp.org/sites/ default/files/hdr 1990 es completo nostats.pdf

PreBISCH, R. (1959). Commercial Policy in the Underdeveloped Countries, American Economic Review, 44: 251-273.

Radelet, S. (2015). The Great Surge: The Ascent of the Developing World, Nueva York, Simon and Schuster.

Rostow, W. W. (1960). The Stages of Economic Growth, Cambridge, Cambridge University Press.

SEN, A. (1999). Development as Freedom, Nueva York, Alfred A. Knopf.

SHAH, R. J. (2021). "The COVID Charter: A New Development Model for a World in Crisis", Foreign Affairs, 100 (5): 179-191. 